\title{
Does fine needle aspiration from a different nodule other than the dominant nodule provide additional benefit in thyroid diseases with nodules?
}

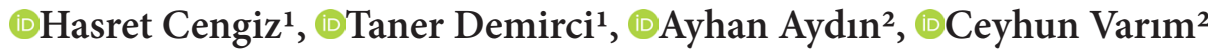 \\ ${ }^{1}$ Sakarya University, Faculty of Medicine, Department of Endocrinology, Sakarya, Turkey \\ ${ }^{2}$ Sakarya University, Faculty of Medicine, Department of Internal Medicine, Sakarya, Turkey
}

Cite this article as: Cengiz H, Demirci T, Aydın A, Varım C. Does fine needle aspiration from a different nodule other than the dominant nodule provide additional benefit in thyroid diseases with nodules?. J Health Sci Med 2021; 4(5): 680-685.

\begin{abstract}
Objectives: The incidence of thyroid nodules has increased significantly and malignancy detected in $5-15 \%$ of them. While biopsy is recommended for all nodules larger than $1 \mathrm{~cm}$ in multinodular goiter, this is practically not possible in many patients. In addition, the relationship between nodule size and malignancy is not clear. We aimed to examine the value of additional biopsy from a nondominant nodule in terms of changing treatment and follow-up decisions and the relationship between nodule size and malignancy risk.

Material and Method: Patients ( $\mathrm{n}=2.541)$ with thyroid nodules who applied to our clinic for various indications and performed fine needle aspiration between January 1, 2016 and March 1, 2021 were included in the study. Some of our patients with multinodular goiter were biopsied from a second additional nodule. Cytologic evaluations reported according to the Bethesda system. Pathology reports of the operated patients were scanned retrospectivelly.

Results: Fine needle aspiration biopsy was performed from a total of 3382 nodules of 2541 patients. The average age of our patient group was 56 (46-65) and $79 \%$ of them were women. When a comparison was made between nodule size and malignancy rate; the highest malignancy rate was detected in nodules between $1-2 \mathrm{~cm}(61.8 \%)$. Finally a diagnosis of Bethesda- $4,-5,-6$ was reached in only $7(0.9 \%)$ of 823 patients who underwent additional biopsy from nondominant nodule.

Conclusion: The value of an additional biopsy from a second nodule in terms of changing follow-up is very low and not significant and most of the cancers arise from nodules between $1-2 \mathrm{~cm}$. According to our study, the assumptions that the malignancy risk increases as the nodule size or nodule count increase were not found to be correct.
\end{abstract}

Keywords: Thyroid nodule, fine needle aspiration biopsy, thyroid cancer

\section{INTRODUCTION}

Nodularity in thyroid is increasingly detected because of incidental detection on various imaging procedures and increased rate of neck ultrasonography due to thyroid diseases. While the frequency of palpable thyroid nodules is between $4-7 \%$ with the use of high resolution ultrasonography, this rate has increased to around 19$67 \%$. Prevalence increases with age and 3-4 times more in women (1-3). Clinically, the most important aspect of thyroid nodules is that $5-15 \%$ of them are found to be malignant. According to the literature cancer risk of palpable and nonpalpable nodules are similar (13 ). Thyroid cancer is the most common cancer among endocrine cancers and constitutes $1 \%$ of all malignant neoplasms $(4,5)$. Ultrasound-guided fine needle aspiration biopsy (FNAB) has become the gold standard method for the evaluation of thyroid nodules $(1,2)$.

According to a large meta-analysis published in 2013, multinodular goiter (MNG) is reported to be less malignant than solitary nodules especially in iodinedeficient areas (6). Currently similar malignancy rates are given in solitary thyroid nodule and multinodular goiter in the literature (7-9). The average malignancy rate for MNG is defined as $15 \%$ (between $4-36 \%$ ), and around $10-21 \%$ for solitary nodule $(10,11)$. Biopsy recommended only from the dominant nodule in some studies, while in others it is emphasized that biopsy should be performed from every nodules that exceed $1 \mathrm{~cm}$ or with suspicius ultrasound features (7). 
According to the current ATA (American Thyroid Association) and AACE (American Association of Clinical Endocrinology) guidelines, biopsy from all nodules exceeding $1 \mathrm{~cm}$ and/or with suspicious US features, and if this is not possible, biopsy from the dominant nodule of coelescent nodules with the same ultrasonographic features is recommended $(12,13)$.

It has not been clarified yet biopsy of the nondominant nodules will affect the treatment and follow-up decision in MNG. In addition, it is not clear whether the risk of malignancy increases with the increased nodule size. We aimed to find out the answer of these two questions in our study.

\section{MATERIAL AND METHOD}

Ethical approval was obtained from the Sakarya University Faculty of Medicine Non-interventional Clinical Researchs Ethics Committee (Date: 11.05.2021, Decision No: E-71522473-050.01.04-32204-321). All procedures were carried out in accordance with the ethical rules and the principles of the Declaration of Helsinki.

Patients older than 18 who had diagnosed or suspected various thyroid diseases and underwent FNAB from one or more nodules between January 1, 2016 and March 1, 2021 were included in the study. Children, pregnant women, patients with a history of radiation exposure to the neck region, and with familial thyroid cancer history, and patients with a current diagnosis of thyroid cancer were excluded. Serum free T3, free T4, TSH (Thyroid Stimulating Hormone) levels were measured by the chemiluminescent microparticle immunological method in the Abbott Architect I $2000 \mathrm{SR}^{\oplus}$ device. Thyroid and neck ultrasonographies (US) were performed by Endocrinology and Metabolism Physicians with a B Mode High Resolution USG device (Logic 9, General Electric $\mathrm{USA}^{\circ}$ ) with a $13 \mathrm{mHz}$ linear probe. In the ultrasonographic evaluation; size of the thyroid tissue in all three planes, echogenicity, doppler blood supply, the detailed location of the nodules their diameters, borders, echogenicity and ultrasonographic features (cystic content, spongioform appearance, microcalcification, macrocalcification foci, etc.) and doppler blood supply charasteristics were specified.

Thyroid scintigraphy was performed before FNAB in patients whom TSH values were at the lower limit of normal and low. The procedure was done with a gamma camera connected to a pinhole collimator.Twenty minutes after intravenous injection of $5 \mathrm{mci}$ Tc99mpertechnetate, anteroposterior and oblique images were taken and thyroid tissue activity and Tc99m uptake and nodule activities were determined and interpreted by Nuclear Medicine Physicians.
Ultrasound guided FNAB was performed by experienced Endocrinology and Metabolism Physicians on medically indicated patients. The patients were informed in detail about the procedure and their written consents were obtained. The procedure was performed under sterile conditions with a $10 \mathrm{ml}$ syringe combined with a 23 gauge needle without local anesthesia. The target nodule was reached under US and then multiple multidirectional passages were made by applying negative pressure. The process was terminated by taking enough material into the syringe. The samples taken were placed in liquidbased cytology tubes containing 95\% ethanol and sent to pathology. The patients generally well-tolerated the procedure and there were no major complications. Tissue materials were examined by experienced pathologists and reported according to the Bethesda system (14).

Surgical operations were performed by general surgeons or otolaryngologists. Lobectomy+isthmectomy or near total or total thyroidectomy procedures were applied to the patients in accordance with their disease. Tissue materials were examined by experienced pathologists.

Laboratory, ultrasonographic data and cytology and pathology reports of the patients were retrospectively scanned from the hospitals online database system. The locations of dominant and nondominant second nodules, which were biopsied, Bethestda classifications, and tissue diagnoses were verified. Biopsied and excised nodules were matched as accurately as possible with the ultrasonographic data.

Statistical analyses were performed by using SPSS version 22 software. The suitability of the variables to normal distribution was examined using visual (histogram and probability graphs) and analytical methods (Kolmogorov-Smirnov). Categorical variables were described as frequencies and percentages. According to the results of these analyzes, the variables of age, TSH, and FT4 levels were not normally distributed. Descriptive analyses were performed using the median and interquartile range (using frequency tables for ordinal variables) for non-normally distributed variables.

\section{RESULTS}

Two thousand five hundred forty one patients with biopsied 3382 nodüles were included in the study. The median age (IQR) value of the patients was 56 (46-65) and the female/male ratio was $2007 / 534(79.0 \% / 21.0 \%)$. TSH (for $\mathrm{n}=1423$ ) and fT4 (for $\mathrm{n}=1367$ ) median (IQR) values were $0.65 \mathrm{mIU} / \mathrm{L}(0.23-1.45)$ and $12.2 \mathrm{pmol} / \mathrm{L}$ (11.2-13.4), respectively. The clinical characteristics and laboratory findings of the patients and the 
characteristics of the nodules are summarized in Table 1. According to TSH levels (for $n=1,423), 596$ (41.9\%) patients were hyperthyroid, 32 were hypothyroid $(2.2 \%)$ and $795(55.9 \%)$ were euthyroid. Fine needle aspiration was performed from at least one nodule of 2541 patients. According to the cytologic evaluation; $588(23.1 \%)$ nodules were category-1, $1608(63.3 \%)$ were category-2, $272(10.7 \%)$ were category-3, 19 $(0.7 \%)$ were category- 4,39 (1.5\%) were category-5 and $15(0.6 \%)$ were in category- 6 .

\begin{tabular}{|c|c|}
\hline & Results \\
\hline Age, years & $56(45-65)$ \\
\hline TSH, mIU/L & $0.65(0.23-1.45)$ \\
\hline \multicolumn{2}{|l|}{ Gender, n (\%) } \\
\hline Female & $2007(79.0)$ \\
\hline Male & $534(21.0)$ \\
\hline First nodüle, n (\%) & $2541(100)$ \\
\hline Maximum diameter (mm) & $15.0(10.0-20.0)$ \\
\hline $\min -\max$ & 3-70 \\
\hline \multicolumn{2}{|l|}{ Location, $\mathbf{n}(\%)$} \\
\hline Right & $1208(47.5)$ \\
\hline Left & $1136(44.7)$ \\
\hline Isthmus & $197(7.8)$ \\
\hline Second (another) nodüle, $n(\%)$ & $841(100)$ \\
\hline Maximum diameter $(\mathrm{mm})$ & $15.0(10.0-20.0)$ \\
\hline $\min -\max$ & $5-60$ \\
\hline \multicolumn{2}{|l|}{ Location, n (\%) } \\
\hline Right & $386(45.9)$ \\
\hline Left & $363(43.2)$ \\
\hline Isthmus & $92(10.9)$ \\
\hline Tissue diagnosis, n (\%) & $230(100)$ \\
\hline Benign & $154(67.0)$ \\
\hline Papillary thyroid cancer & $66(28.7)$ \\
\hline Follicular thyroid cancer & $3(1.3)$ \\
\hline NIFTP & $4(1.7)$ \\
\hline vWDT-UMP & $2(0.9)$ \\
\hline Anaplastic carcinoma & $1(0.4)$ \\
\hline
\end{tabular}

Surgery was decided in $73(2,9 \%)$ of 2541 patients because of one or two nodules cytologic evaluation were compatible with Bethesda categories-4,5 and 6 . The remaining 2,468 patients were decided for followup or re-biopsy because the result was category-1,2, and 3. In 823 patients $\mathrm{FNAB}$ was performed from different nodules at different times. Cytologic result of $816(99.1 \%)$ of them were evaluated as compatible with Bethesda category-1,2, and 3, only 7 (0.9) of them were compatible with categories 4,5 and 6 and referred to surgery (Figure 1). Eighty-eight (5.5\%) of the patients whom FNAB result were compatible with category-2 (benign) were operated for different reasons. Pathological evaluation of 11 (12.5\%) of these 88 operated patients was compatible with malignancy (Figure 2).

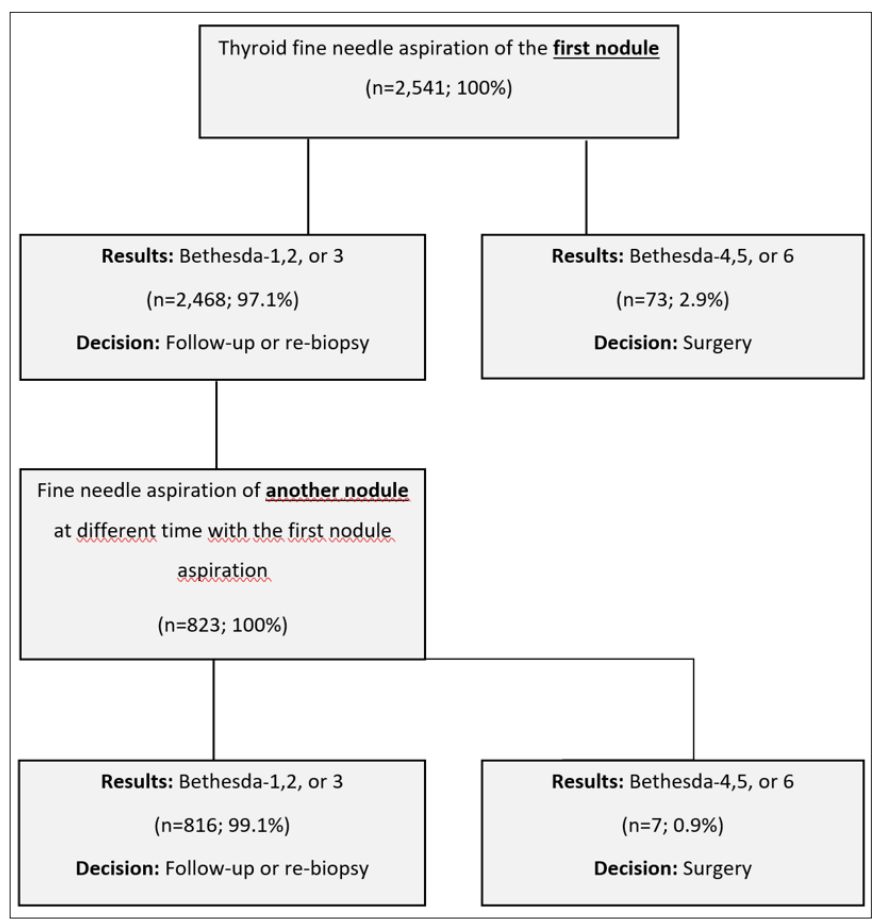

Figure 1. Diagram showing results of thyroid fine needle aspiration

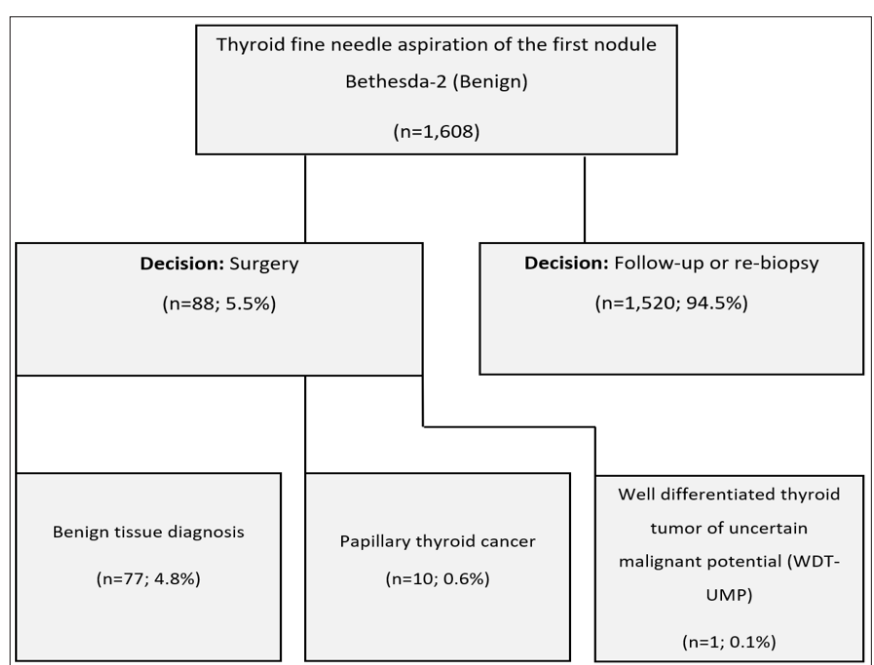

Figure 2. Diagram showing results of thyroid fine needle aspiration

The median (IQR) value of 76 patients who were operated and whose pathology was malignant was 47 (35-55.8) and the majority were women $(n=57,75 \%)$. When analyzed according to nodule size, the tumor was mostly in the group with $10-10.9 \mathrm{~mm}(\mathrm{n}=47,61.8 \%)$ (Table 2). 


\begin{tabular}{|c|c|}
\hline & Results $(n=76)$ \\
\hline Age, years & $47.0(39.0-55.8)$ \\
\hline \multicolumn{2}{|c|}{ Gender, n (\%) } \\
\hline Female & $57(75.0)$ \\
\hline Male & $19(25.0)$ \\
\hline \multicolumn{2}{|c|}{ Nodule size (maximum diameter), $\mathrm{mm}$} \\
\hline$<10$ & $8(10.5)$ \\
\hline $10-10.9$ & $47(61.8)$ \\
\hline $20-39.9$ & $16(21.1)$ \\
\hline$\geq 40$ & $5(6.6)$ \\
\hline \multicolumn{2}{|c|}{ Nodule location, n (\%) } \\
\hline Right lobe & $34(44.7)$ \\
\hline Left lobe & $31(40.8)$ \\
\hline Isthmus & $11(14.5)$ \\
\hline
\end{tabular}

\section{DISCUSSION}

High-resolution ultrasonography is now widely used in our country and nodule biopsy is almost completely performed by US. Therefore the rate of detecting thyroid nodules and the accuracy of FNAB is increasing.

The average age of our patient group was 56 (45-65) and $79 \%$ of them were women. The mean age of cancer group was found to be 47 (39-55.8) and $75 \%$ of them were female. The average age of our nodule and cancer patients is consistent with the literature $(4,10,11,15)$. Of the 76 patients with malignancy, $66(86 \%)$ were papillary thyroid carcinoma, 3 (3.9\%) were follicular thyroid carcinoma, and these rates are also consistent with the literature $(4,7,10,16)$.

According to the guidelines; the malignancy rate of all palpable and nonpalpable nodules were assumed to be equal and recommended biopsy from all nodules above $1 \mathrm{~cm}$; If this is not possible, biopsy is recommended from the largest one of the coelescent nodules with the same character (dominant nodule) or the nodule with suspicius ultrasonographic findings $(12,13)$. However the probability of malignancy in MNG was generally found to be equal to or lower than solitary nodüle in the literature (6-10). In clinical practice, performing multiple biopsy from a patient from many nodules is more difficult to tolerate, time-consuming and costly (7). Therefore, we wondered how valuable the multiple nodule biopsy procedure is in terms of patient follow-up and in making the surgical decision. According to our data, only 7 of the 823 patients was malignant who had a second nodule biopsy; this led to an additional surgery decision of $0.9 \%$ according to the total number of patients. In other words, we found that biopsy from an additional nodule detected malignancy in very few patients and changed the treatment decision.
When studies that performed nodule biopsies from nondominant nodules in MNG were examined, in the study of Frates et al. (7) 3483 nodules of 1985 patients were biopsied. According to this study, in patients with multiple nodules larger than $10 \mathrm{~mm}, 72 \%$ of cancers were detected in the largest nodule, and $46 \%$ were multifocal. According to the results of the same study, the strategy of taking the largest nodule biopsy could detect only $86 \%$ of patients with cancer with two nodules, whereas approximately $50 \%$ of patients with cancer with three or more nodules. In the study of Paksoy et al. (11) $35.7 \%$ of the detected malignancies were found in the nondominant nodule and multiple nodule biopsy, preferably from different lobes, was recommended. Arisoy et al. (16) was detected $65.5 \%$ of a single $34.5 \%$ multifocal cancer in 142 patients, and the cure rate of surgery performed only on the dominant nodule side remained at $65 \%$. In another study, cancer was detected with a rate of $14.3 \%$ and half of the cancer cases detected in nondominant nodules (17). Surgically confirmed 365 cases were examined in the study by Erbil et al. (18) and $59 \%$ of the patients were found to have cancer outside the dominant nodule.

According to the results of these studies; we see that biopsy of one or more nodules other than the dominant nodule in MNG changes the diagnosis and treatment decision significantly. In our study the reason that biopsy from the second nodule was not found very effective in the treatment decision may be the second biopsy was performed on nondominant nodules with the same characteristics as the initial nodules and we did not perform additional biopsy in all patients with MNG.

Sensitivity of fine-needle aspiration biopsy in general ranges between $65-98 \%$ and specificity between $72-100 \%$ $(1,10)$. In our study, we performed biopsies on a total of 3382 nodules of 2541 patients, $23.1 \%$ of these patients were found to be nondiagnostic. The nondiagnostic rates in the literature are between $10-28.2 \%$ and our series is compatible with the literature (19). Additionally 88 patients with benign FNAB (Bethesda category 2) underwent surgery for different reasons and malignancy was detected in $11(12.6 \%)$ of them. According to the literature, false negativity rate of FNAB is generally between $1-10 \%$, but in the study of Arisoy et al. this rate rises up to $17 \%(3,16)$. The reason for the false negativity rate being slightly higher than the literature in our study may be that all biopsied patients were not undergoing surgery and it was not clarified whether all of the malignancies arised from the nodules that we performed biopsy.

Currently surgery is recommended for nodules above $4 \mathrm{~cm}$, even if the nodule is benign. The high rate of false negativity in FNAB in these nodules supports this recommendation $(4,18)$. It is also a matter of curiosity 
whether the size of the nodule affects the possibility of malignancy. In our study, most of the malignancies were detected in nodules between 1 and $2 \mathrm{~cm}(61,8 \%)$, while this rate remained at $10.5 \%$ in subscentimetric nodules and $6,6 \%$ in above $4 \mathrm{~cm}$ nodules. According to a systematic meta-analysis, an increase in the risk of malignancy above $2 \mathrm{~cm}$ has been reported (20). Polyzos et al. (21) was found An increased risk in nodules larger than $4 \mathrm{~cm}$. Kamran et al. (22) was found a slightly increased risk of malignancy in nodules larger than $2 \mathrm{~cm}(<2 \mathrm{~cm} 10.5 \%$ vs $>2 \mathrm{~cm} \mathrm{15 \% ).} \mathrm{In} \mathrm{the} \mathrm{studies} \mathrm{of} \mathrm{Shrestha} \mathrm{(7)} \mathrm{and} \mathrm{Frates} \mathrm{et}$ al. (23) no significant difference was found in malignancy rates according to the size of the nodule. On the other hand Cavallo et al. (4) was found significantly increased malignancy rates in nodules smaller than $2 \mathrm{~cm}$ and $\mathrm{Er}$ et al. (5) found increased malignancy rate of less than $1 \mathrm{~cm}$. When our results are evaluated together with the results of other similar designed studies, it shows that nodule size does not play a very significant role according to the risk of malignancy.

Our study is a single center study designed retrospectively. We could not clarify in a few patients whether the nodules that were biopsied and were found to be malignant during surgery are the same nodules. Fortyone percent of our patient group consists of hyperthyroidic patients. Although there are publications in the literature that hyperactive nodules have a similar malignancy risk with normoactive and hypoactive nodules (24), according to current guidelines, biopsy is not recommended because it is known that the possibility of malignancy in hyperactive nodules is very low $(2,3,11,12)$. We performed Tc99m scintigraphy in hyperthyroidic patients for avoiding biopsy from autonomic nodules, however there is still the possibility of being hyperactive nodules among the nodules we biopsied and therefore the rate of additional malignancy detected in the second nodule may found to be low.

\section{CONCLUSION}

The relationship between nodule size and malignancy risk was examined in our study, and the highest rate of malignancy was found in nodules between $1-2 \mathrm{~cm}$. In addition the value of additional biopsy performed from a second nodule in multinodular goiter was found to be very low in terms of changing follow-up and deciding surgery. Although it is a single center study we presented our study with a considerable number of cases and power. We found nondiagnostic and false negativity rates in accordance with the literature and well documented the biopsy and surgical data. We think that the net results of our study will contribute to the literature. Multicenter, large randomized controlled studies are needed to achieve clearer results.

\section{ETHICAL DECLARATIONS}

Ethics Committee Approval: Ethical approval was obtained from the Sakarya University Faculty of Medicine Non-interventional Clinical Researchs Ethics Committee (Date: 11.05.2021, Decision No: E-71522473-050.01.04-32204-321).

Informed Consent: Because the study was designed retrospectively, no written informed consent form was obtained from patients.

Referee Evaluation Process: Externally peer-reviewed.

Conflict of Interest Statement: The authors have no conflicts of interest to declare.

Financial Disclosure: The authors declared that this study has received no financial support.

Author Contributions: All of the authors declare that they have all participated in the design, execution, and analysis of the paper, and that they have approved the final version.

\section{REFERENCES}

1. Ross DS,Cooper DS, Mulder JE, et al. Overview of Thyroid Nodule Formation. UpToDate Clinical Review. Online Available at http://www.uptodate.com Searched at May 2021.

2. Ross DS,Cooper DS, Mulder JE, et al. Diagnostic Approach to and Treatment of Thyroid Nodules. UpToDate Clinical Review. Online Available at http://www.uptodate.com Searched at May 2021.

3. Burman KD, Wartofsky L. Clinical practice thyroid nodules. N Engl J Med 2015; 10: 2347-56.

4. Cavallo A, Johnson DN, White MG, et al. Thyroid nodule size at ultrasound as a predictor of malignancy and final pathologic size. Thyroid 2017; 27: 641-50.

5. Er S, Akın T, Baba S, et al. Relationship between Thyroid Nodule Diameter and Malignancy: Nodüle Diameter Actually Increase Probability of Malignancy? Akd Med J 2017; 3: 191-6.

6. Brito JP, Yarur AJ, Prokop LJ, McIver B, Murad MH, Montori VM. Prevalence of thyroid cancer in multinodular goiter versus single nodule: a systematic review and meta-analysis. Thyroid 2013; 23: 449-55.

7. Frates MC, Benson CB, Doubilet PM, et al. Prevalence and distribution of carcinoma in patients with solitary and multiple thyroid nodules on sonography. J Clin Endocrinol Metab 2006; 91: 3411-7.

8. Lin YS, Wu HY, Yu MC, Hsu CC, Chao TC. Patient outcomes following surgical management of multinodular goiter: Does multinodularity increase the risk of thyroid malignancy? Medicine (Baltimore) 2016; 95: e4194.

9. Sachmechi I, Miller E, Varatharajah R, et al. Thyroid carcinoma in single cold nodules and in cold nodules of multinodular goiters. Endocr Pract 2000; 6: 5-7.

10.Keh SM, El-Shunnar SK, Palmer T, Ahsan SF. Incidence of malignancy in solitary thyroid nodules. J Laryngol Otol 2015; 129: 677-81.

11.Paksoy N, Yazal K, Corak S. Malignancy rate in nondominant nodules in patients with multinodular goiter: Experience with 1,606 cases evaluated by ultrasound-guided fine needle aspiration cytology. Cytojournal 2011; 8: 19-28. 
12.Haugen BR, Alexander EK, Bible KC, et al. American thyroid association management guidelines for adult patients with thyroid nodules and differentiated thyroid cancer: the american thyroid association guidelines task force on thyroid nodules and differentiated thyroid cancer. Thyroid 2016; 26: 1-133.

13. Gharib H, Papini E, Garber JR, et al. American association of clinical endocrinologists, american college of endocrinology, and associazione medici endocrinology medical gurdelines for clinical practice for the diagnosis and management of thyroid nodules 2016 Update. AACE/ACE/AME task force on thyroid nodules. Endocr Pract 2016; 22: 622-39.

14. Cibas ES, Ali SZ. The 2017 Bethesda system for reporting thyroid cytopathology. Thyroid 2017; 27:1341-6.

15.Erdem H, Yıldırım Ü, Özaydın İ, et al. Retrospective comparison of histopathologic results of thyroid fine-needle aspiration biopsies. Konuralp Tip Derg 2012; 4: 26-30.

16. Arısoy K, Köksoy FN, Gönüllü D, Ayyıldız İğdem A, Kuru B. The relationship of thyroid cancer with dominant nodule in patients with nodular goiter who underwent total thyroidectomy and had thyroid carcinoma. Ulusal Cerrahi Derg 2012; 28: 182-85.

17. Yong JS, Loh KS, Petersson BF, Thong M. Multinodular goiter: A study of malignancy risk in nondominant nodules. Ear Nose Throat J 2017; 96: 336-42.

18. Erbil Y, Barbaros U, Salmaslioglu A, et al. Effect of thyroid gland volume in preoperative detection of suspected malignant thyroid nodules in a multinodular goiter. Arch Surg 2008; 143: 558-63.

19. Mehanna R, Murphy M, McCarthy J, et al. False negatives in thyroid cytology: impact of large nodule size and follicular variant of papillary carcinoma. Laryngoscope 2013; 123: 1305-09.

20. Shin JJ, Caragacianu D, Randolph GW. Impact of thyroid nodule size on prevalence and post-test probability of malignancy: a systematic review. Laryngoscope 2015; 125: 263-72.

21.Polyzos SA, Kita M, Efstathiadou Z, et al. The use of demographic, ultrasonographic and scintigraphic data in the diagnostic approach of thyroid nodules. Exp Clin Endocrinol Diabetes 2009; 117: 159-64.

22. Kamran SC, Marqusee E, Kim MI, et al. Thyroid nodule size and prediction of cancer. J Clin Endocrinol Metab 2013; 98: 564-70.

23. Shrestha M, Crothers BA, Burch HB. The impact of thyroid nodule size on the risk of malignancy and accuracy of fine-needle aspiration: a 10-year study from a single institution. Thyroid 2012; 22: 1251-6.

24. Baser H, Topaloglu O, Bilginer MC, et al. Are cytologic and histopathologic features of hot thyroid nodules different from cold thyroid nodules? Diagn Cytopathol 2019; 47: 898-903. 